\section{Management of outpatients}

SIR,-Two patients of our practice have attended the outpatient departments of different teaching hospitals for many years (seven years in one case and 14 in the other). During that time they have not seen the consultant in charge of the clinic and the hospital letters have come from a series of registrars. Furthermore, the contents of the letters suggest that the patients have not been subject to recurrent full assessment but have been treated for their current symptoms. They have not been considered for discharge.

Many hospital consultants occasionally review the longstanding outpatients in their care, but this perhaps should be more clearly defined in the job specification of the role of the consultant in outpatients. There should be an introduction of training for junior medical staff in this management function.

\section{London NW10}

R LAW

\section{Extending the role of the clinical nurse}

SIR,-I read with interest your leading article "Extending the role of the clinical nurse" (11 November, p 1320 (Community health. nurses have been safely acting as primary purveyors of health care in Canada's north for many years.

The northern nurse practitioner is employed by the Canadian Department of Health and Welfare and is in a position of respondeat superior, deemed to be working under the direction of a physician. These nurses are employed in nursing stations across Canada's north, often hundreds of miles from the nearest doctor. All nurses have access to consultation with a physician by telephone or radio and physicians visit the isolated settlements on varying schedules of regularity.

The nurse may refer patients to a physician in an emergency or for follow-up by a physician within the settlement if it is deemed necessary. Much of the regular general practitioner work load is carried out by these nurses, including such tasks as history taking, diagnosis, prescription, dispensing of medications, $x$ raying of chest and limbs, and suturing. Emergency care of patients may include intravenous therapy and cardiopulmonary resuscitation. Prenatal and postnatal care and the delivery of uncomplicated obstetric patients (gravida 2-4,) are also the responsibility of the nurses. Besides carrying out regular treatment at clinics the nurse practitioner is also responsible for the public health service in her area.

Training for clinical nurses is at present offered in a four-month course at the University of Alberta, but unfortunately it is not possible for all nurses employed by medica services to attend such courses. Those unable to attend find that previous nursing experience stands them in good stead and enables them to function adequately if working alongside more experienced nurse practitioners.

I agree that a nurse is not a physician substitute but with experience and, preferably, additional training she may become a valuable asset for a busy practice. At a time when health costs are increasing exponentially I submit that a nurse practitioner orientated towards health teaching cannot but be advantageous.

It may be of interest to your readers to know that there are probably many nurses in the United Kingdom who have functioned safely as nurse practitioners in northern Canada and who are at present being underused in hospitals or district nursing positions.

\section{Barbara J Edgecombe-GreEN}

Edmonton,

Edmonton,
Alberta, Canada

\section{What price the new consultant contract?}

SIR,-Mr T MacFarlane (20 January, p 208) wrote a thoughtful article on the new contract for consultants, expressing reservations about some aspects of the agreement reached between CCHMS and Government. In particular, he expressed concern about the lack, in any of the relevant documents, of a definition of the notional half day. I felt that I should comment on this particular issue, as it is fundamental to the concepts on which the new contract is based.

When the profession agreed to explore the possibility of fundamental change in the terms under which consultants were employed in the National Health Service, it made clear to its negotiators that any contract which was developed must continue to be appropriate to professional people and that it must not be such as to encourage "clock-watching" attitudes, much less clocking in and clocking out. For this reason, the unit which was chosen as a basis for the new contract was the notional half day, defined as at present, in paragraph 61 of the terms and conditions of service (which is included unchanged in appendix 2 to the contract offer).

Throughout negotiations it was accepted on both sides that the nature of consultant work did not lend itself to the use of a tightly defined unit and that the right of the consultant to adjust his precise time schedule from day to day as pressure of work demanded was as important to the successful operation of the Health Service as it was to the feeling of professional independence enjoyed by the consultant. Over the 30 years that the NHS has existed, the present very general definition of the notional half day has come to be well understood by consultants and health authorities. To have renegotiated the definition must have created greater precision and a more restrictive interpretation by both sides.

When I have spoken on this subject, both to CCHMS and to meetings of consultants round the country, I have frequently used the expression "flexibly worked" to explain my understanding of the notional half day in both the present and the new contract. The source of this phrase, which sums up the position admirably, was a letter to the profession, written on behalf of the previous secretary of state in 1975. I have often gone on to illusrate the point by remarking that one of my own NHDs can usually be completed in $2 \frac{1}{2}$ hours but that on the day of my principal operating session one NHD commonly lasts for $4 \frac{1}{2}$ hours or even longer, this being the nature of the NHD, worked flexibly. The continued use of the existing definition of a notional half day will allow this type of arrangement to continue after the introduction of the new contract. Indeed, it is difficult to see how the Health Service could be operated on any other basis.

I have every sympathy with my colleagues in the training grades who, because of problems in the past, feel that a very precise definition is necessary as a basis for their contractual arrangements; but the nature of consultant responsibility is different from that of any other hospital doctor and such responsibility cannot be discharged on the basis of a closely defined contractual unit. London WC1

\section{State of community medicine}

SIR,-After reading the two reports (17 February, $p$ 503) concerning the future training of community health doctors it is difficult to escape the impression that some obsolete patterns of the past are still being used as blueprints for the future. Perhaps, like the Court Committee ${ }^{1}$ before them, members of both working parties embraced the philosophy of modern doctoring too warmly to allow them to raise their sights beyond the immediate and middle future to the distant future of community child care training.

Today doctors are becoming trained as technologists of increasing sophistication and taught to be decisive in their quest for correct answers to disease, because this is what modern society demands of them. The community paediatrician however has no ready answers, and must therefore patiently learn to recognise the interplay between physical, emotional, and social factors before attempting much in the way of specific answers to community clinical problems.

If community child care training is to develop logically then surely some fundamental changes should occur in undergraduate preclinical thinking, allowing psychology, anthropology, and medical sociology to carry a status in our medical schools equal to that of chemistry, physics, and anatomy. Were this elementary change to be implemented immediately it would still take about 10 years for the first batch of suitably trained community paediatricians to emerge as the new kind of doctors needed to cope with the challenge posed by current clinical community paediatrics.

Peter J Rawlinson GWYNNE V LEWIS

Health Department
Ipswich, Suffolk

Committee on Child Health Services, Fit for the Future, London, HMSO, 1976.

\section{Consultant milage allowances}

SIR,-May I be permitted through your column to add one further experience of the DHSS's attitude to travelling expenses for consultants using their own cars in the pursuance of their professional commitments?

As a result of the reorganisation of the child and adolescent psychiatric service in the district my headquarters were moved some 11 miles. The bulk of my clinical work is domiciliary based (without payment of a domiciliary fee) and community orientated, which has allowed closure of the children's hospital in the district. I now find that a considerable amount of my milage (some 4800 miles $(7700 \mathrm{~km}$ ) per year) which was previously paid at official rate is now paid at excess travelling expenses rate, even though this milage would have been driven under the original arrangement and therefore attracted the official milage rate. The Department is therefore able to save the pay- 